\title{
Avaliação na educação infantil e a pedagogia da relação e da escuta: documentar e refletir sobre a experiência educativa
}

\begin{abstract}
Resumo: O propósito do ensaio é fomentar o debate acerca da avaliação na Educação Infantil, enquanto prática de registro e acompanhamento do desenvolvimento das crianças, que resulta na produção de documentação específica sobre seus processos de desenvolvimento e aprendizagem nessa etapa educacional. Apresenta reflexões sobre essa temática, amparadas na definição de avaliação para a Educação Infantil presente na legislação educacional brasileira. Teoricamente se subsidia na Pedagogia da Relação e da Escuta, idealizada por Loris Malaguzzi. Além disso, para elucidar o conceito de avaliação, descreve uma experiência desenvolvida na Unidade Universitária Federal de Educação Infantil Núcleo de Desenvolvimento da Criança, da Universidade Federal do Ceará.
\end{abstract}

Palavras-chave: Avaliação na Educação Infantil. Crianças. Acompanhamento do desenvolvimento. Documentação Pedagógica.

\section{Evaluation in early chidhood education and the pedagogy of relation and listening: documenting and reflecting on the educational experience}

Abstract: The objective of this essay is to foster the debate about evaluation in Early Childhood Education, as a practice of recording and monitoring children development which results in the production of specific documentation regarding their development and learning processes in the pre-school period. It presents reflections upon this theme, based on the Brazilian legislation related to evaluation in Early Childhood Education. Its theoretical framework is the Pedagogy of Relation and Listening, formulated by Loris Malaguzzi. In addition, to elucidate the concept of evaluation, it describes an evaluation experience developed in Child Development Center of the Federal University of Ceará.

Keywords: Evaluation in Early Childhood Education. Children. Development Monitoring. Pedagogical Documentation.

\footnotetext{
1 Doutoranda em Educação pela Universidade Federal do Ceará (UFC) e mestra em Educação pela mesma Universidade. Professora da UFC e desenvolve suas atividades na Unidade Universitária Federal de Educação Infantil Núcleo de Desenvolvimento da Criança (UUNDC). E-mail: jorgianaricardop@gmail.com

2 Doutora em Educação nos Anos Iniciais pela Universidade do Arizona - Estados Unidos. Professora aposentada da Universidade Federal do Ceará (UFC) e professora colaboradora no Programa de Pós-Graduação em Educação da UFC. E-mail: fatimass@uol.com.br
} 


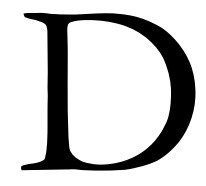

e acordo com a Lei de Diretrizes e Bases da Educação Nacional (LDBEN), a avaliação na Educação Infantil deve ocorrer “[...] mediante acompanhamento e registro do desenvolvimento das crianças, sem o objetivo de promoção, mesmo para o acesso ao ensino fundamental" (BRASIL, 1996, Art. 31, I). As novas Diretrizes Curriculares Nacionais para Educação Infantil (DCNEI), aprovadas pelo Conselho Nacional de Educação (CNE), em 2009, também definem a Avaliação na Educação Infantil, enquanto prática de acompanhamento do desenvolvimento das crianças. Em seu Art. 10, essas diretrizes determinam que "as instituições de Educação Infantil devem criar procedimentos para o acompanhamento do trabalho pedagógico e para a avaliação do desenvolvimento das crianças, sem objetivo de seleção, promoção ou classificação" (BRASIL, 2009).

É importante pontuar que as novas DCNEI de 2009 se baseiam nos mesmos princípios das DCNEI de 1999, mas os ampliam, buscando atender e dialogar com os novos desafios postos para a área. Não obstante a relevância de todas as inovações presentes nas DCNEI/2009, é preciso destacar algumas delas: 1) a presença de uma definição inovadora de currículo para Educação Infantil, que busca garantir experiências e aprendizagens que não antecipem conteúdos do Ensino Fundamental, tais como a demanda equivocada e cada vez mais precoce de alfabetização das crianças pequenas ${ }^{3}$; 2) a definição das interações e da brincadeira como eixos norteadores das práticas pedagógicas que compõem a proposta curricular; 3) o detalhamento do que as práticas pedagógicas precisam garantir em termos de experiências de aprendizagem; 4) a demarcação dos aspectos que o acompanhamento do trabalho pedagógico e a avaliação do desenvolvimento das crianças devem garantir. Essa última, objeto de interesse desse ensaio, está explicitado nos cinco incisos do Art. 10 das DCNEI:

\begin{abstract}
I - a observação crítica e criativa das atividades, das brincadeiras e interações das crianças no cotidiano; II - utilização de múltiplos registros realizados por adultos e crianças (relatórios, fotografias, desenhos, álbuns etc.); III - a continuidade dos processos de aprendizagens por meio da criação de estratégias adequadas aos diferentes momentos de transição vividos pela criança (transição casa/instituição de Educação Infantil, transições no interior da instituição, transição creche/pré-escola e transição pré-escola/Ensino Fundamental); IV - documentação específica que permita às famílias conhecer o trabalho da instituição junto às crianças e os processos de desenvolvimento e aprendizagem da criança na Educação Infantil; V - a não retenção das crianças na Educação Infantil. (BRASIL, 2009).
\end{abstract}

Nesse contexto, vale ressaltar que é recente o detalhamento na legislação educacional a respeito do que o acompanhamento do trabalho pedagógico e a avaliação do desenvolvimento das crianças devem garantir, conforme expresso nos incisos do Art. 10 das DCNEI/2009. Bem como é incipiente a problematização dessa temática. Diversos estudos (CIASCA; MENDES, 2009; NEVES, 2012; PAZ, 2005) advertem que são poucas as pesquisas sobre avaliação na Educação Infantil. Portanto, as definições

\footnotetext{
${ }^{3}$ Nesse sentido, a Resolução n 5 DCNEl/2009 determina que a proposta pedagógica das instituições de Educação Infantil, na transição para o Ensino Fundamental, "[...] deve prever formas para garantir a continuidade no processo de aprendizagem e desenvolvimento das crianças, respeitando as especificidades etárias, sem antecipação de conteúdos que serão trabalhados no Ensino Fundamental" (BRASIL, 2009, ART. 11).
} 
das DCNEI/2009 em relação à avaliação convocam pesquisadores da área, professores e gestores educacionais e escolares dessa etapa da educação a refletir sobre a responsabilidade das políticas públicas, das instituições de Educação Infantil e dos professores no âmbito da avaliação.

Assim, em virtude das definições legais brasileiras para a avaliação em instituições de Educação Infantil (BRASIL, 1996, 2009), é necessário afirmar que elas são contrárias a qualquer perspectiva de avaliação das crianças que objetivem classificá-las, compará-las ou retê-las na Educação Infantil. Além disso, permitem ponderar que a avaliação na Educação Infantil é uma prática duplamente pedagógica, pois não tem como foco apenas o acompanhamento do desenvolvimento das crianças, visando também às ações de acompanhamento do trabalho pedagógico desenvolvido na instituição. Nesse sentido, é possível utilizar recursos como a observação e o registro das práticas, para documentá-las e colocá-las em análise coletiva, fomentando a reflexão sobre o trabalho institucional e aquele desenvolvido junto às crianças. Essas ações, ao mesmo tempo, contribuem para que os professores adotem esses recursos em suas práticas de acompanhamento do desenvolvimento das crianças, de modo que possam refletir se elas estão se beneficiando ou não das práticas planejadas e desenvolvidas em suas turmas. Esta reflexão poderá reorientar seus planejamentos, suas formas de agir e se relacionar com as crianças.

Neste trabalho, embora conscientes da relevância de procedimentos integrados para o acompanhamento do trabalho pedagógico nas instituições de Educação Infantil e para avaliação do desenvolvimento das crianças, devido aos limites do texto, as reflexões focalizarão especialmente as práticas de acompanhamento do desenvolvimento das crianças.

Nesse contexto, é preciso destacar que a avaliação na Educação Infantil, conforme o que é definido na legislação educacional brasileira, exige do professor assumir a documentação pedagógica como parte de sua prática docente. Todavia, para que esta seja efetivamente implementada nas creches e préescolas é necessário mais do que o empenho individual do professor. Isto porque o processo da documentação implica em diversas aprendizagens por parte dos docentes e coloca inúmeras demandas e desafios tanto para a gestão escolar de instituições de Educação Infantil, como para as políticas públicas de formação inicial e continuada. Vale pontuar que a documentação pedagógica não se resume a simples coleta de dados (GANDINI; GOLDHABER, 2002) para preencher fichas com perguntas prontas que se assemelham a uma anamnese médica. Pelo contrário, ela exige do professor, entre outros aspectos, que reconheça a importância e a intencionalidade da documentação e a atribuição de grande importância às produções das crianças, valorizando o que elas comunicam e dizem a partir de suas múltiplas linguagens (MALAGUZZI, 1999).

Em outras palavras, a prática de documentação das experiências das crianças nas diversas situações vividas no cotidiano da Educação Infantil demanda do professor conhecimentos específicos sobre Educação Infantil que possibilitem o reconhecimento da criança como centro do planejamento curricular. A criança é reconhecida como sujeito competente que "[...] nas relações, interações e práticas cotidianas que vivencia, constrói sua identidade pessoal e coletiva, brinca, imagina, fantasia, deseja, 
aprende, observa, experimenta, narra, questiona e constrói sentidos sobre a natureza e a sociedade [...]", assim sendo, produto e produtor de cultura, sujeito histórico e de direitos (BRASIL, 2009, p. 1).

Nesse sentido, Hoffmann (1996), uma importante referência brasileira em estudos a respeito da avaliação na Educação Infantil, ao discorrer sobre avaliação e desenvolvimento infantil, destaca que "a busca de significados para a avaliação requer o estudo das concepções de Educação Infantil, das teorias do desenvolvimento e das abordagens do processo educativo que delas se originam" (p. 21). Desse modo, a avaliação na Educação Infantil exige do professor “[...] tanto a capacidade de perceber os significados das ações e do comportamento das crianças quanto a habilidade para encontrar palavras adequadas para descrever e interpretar tal comportamento sem diminuir-lhe o valor" (FORTUNATI, 2012, p. 6).

Em relação às concepções sobre Educação Infantil, é fundamental destacar a necessidade do fortalecimento da sua identidade como uma etapa não escolarizante, cujo propósito é assegurar às crianças o acesso a práticas pedagógicas que respeitem seus ritmos, necessidades e interesses e garantam seu desenvolvimento integral. Foi a partir desta concepção que as DCNEI/2009 definiram a Avaliação como uma prática de acompanhamento do desenvolvimento da criança que implica na construção de práticas pedagógicas fundamentadas em Pedagogias da Educação Infantil ${ }^{4}$ abertas ao seu protagonismo.

Nesse âmbito, é imprescindível lembrar que no Brasil os desencontros entre as demarcações legais na esfera educacional e a efetivação destas nas práticas pedagógicas constituem fatos que ocorrem com elevada frequência. Como Campos (2008, p. 27) destaca, "nossa tradição cultural e política sempre foi marcada por essa distância e, até mesmo, pela oposição entre aquilo que gostamos de colocar no papel e o que de fato fazemos na realidade". Vale ressaltar que apesar de a avaliação na Educação Infantil possuir contornos bem definidos na legislação, não há estudos a nível nacional referentes à forma como vem sendo desenvolvida nas creches e pré-escolas públicas e privadas do país. Além disto, os estudos sobre avaliação na Educação Infantil mencionados anteriormente chamam atenção para a necessidade de discussões e pesquisas sobre esse tema. Deste modo, acreditamos que este ensaio poderá colaborar para a ampliação do debate sobre avaliação na Educação Infantil, objetivo deste texto.

A estratégia metodológica adotada neste ensaio é de natureza teórica, tendo como aporte a Pedagogia da Relação e da Escuta, perspectiva pedagógica para o trabalho com a Educação Infantil, desenvolvida na cidade italiana de Reggio Emilia ${ }^{5}$ (MALAGUZZI, 1999). A problemática deste estudo justifica a escolha de bases teóricas comprometidas com concepções de infância, criança e Educação Infantil capazes de contestar perspectivas que negam a diversidade e a heterogeneidade presentes na forma de se pensar essas categorias sociais na atualidade. Tais bases teóricas legitimam a competência da

\footnotetext{
${ }^{4}$ O emprego da expressão Pedagogias da Educação Infantil, no plural, inspira-se em Barbosa (2000) que, ao pluralizar a expressão, destaca seu caráter diverso e múltiplo, expresso até mesmo nos adjetivos que qualificam as Pedagogias como tradicionais, críticas, libertadoras, progressistas, libertárias, feministas etc. A pesquisadora pondera que as teorizações mais universalizantes sobre educação não têm respondido às questões educativas colocadas pelas sociedades e pelas culturas de forma eficaz, assim o mapeamento dessas diferentes Pedagogias faz-se necessário. Nesse sentido, em consonância com a autora, entendemos que: "[...] se as subdivisões das pedagogias podem, por um lado, ser manifestações de fragmentação e de disputas, por outro, quando permanentemente relacionadas e recontextualizadas, auxiliam no aprofundamento das discussões e no avanço dos conhecimentos [...]" (BARBOSA, 2000, p. 23).

${ }^{5}$ Reggio Emilia é uma cidade localizada na região de Emilia Romanha, no norte da Itália. O atendimento oferecido às crianças e suas famílias nas instituições de Educação Infantil do sistema Reggio Emilia são exemplos de um trabalho de boa qualidade, que inspiram reflexões teóricas e práticas em diversos países (EDWARDS; GANDINI; FORMAN, 1999), inclusive no Brasil.
} 
criança para construir conhecimentos sobre si e sobre o mundo e reconhecem o importante papel da Educação Infantil para o desenvolvimento e para as aprendizagens infantis.

Não obstante a relevância do referencial teórico para se discutir a avaliação na Educação Infantil à luz do que é definido na legislação educacional brasileira (BRASIL, 1996; 2009), incorporamos a este ensaio uma experiência concreta de avaliação, desenvolvida em uma instituição pública federal de Educação Infantil.

O diálogo com uma prática concreta se deve à necessidade de reduzir os riscos de cair no que Azanha (1992) chamou de "figurativismo pedagógico". Isto pode ocorrer quando se descreve, se explica ou se busca compreender situações educacionais verdadeiras, atendo-se exclusivamente a princípios ou leis gerais. Este tipo de abordagem, meramente intelectual, se dá em detrimento das determinações específicas e concretas das situações educacionais, como se a abrangência abstrata pudesse dar conta de responder às situações enfocadas.

Este artigo está organizado em cinco partes. Nesta introdução, problematizamos o tema, apresentamos o objetivo, a estratégia metodológica e justificamos a relevância da temática; na segunda seção, discorremos acerca da Pedagogia da Relação e da Escuta, valorosa referência para o entendimento do conceito e da prática de documentação pedagógica, tão importante para a avaliação das crianças em instituições de Educação Infantil brasileiras; na terceira e quarta, focalizamos a experiência desenvolvida na Unidade Universitária Federal de Educação Infantil Núcleo de Desenvolvimento da Criança (UUNDC), da Universidade Federal do Ceará (UFC); e na quinta tecemos algumas considerações finais sobre o assunto, objeto de estudo deste trabalho.

\section{Pedagogia da relação e da escuta: ouvir e documentar sistematicamente o desenvolvimento e as aprendizagens das crianças}

Malaguzzi, o principal idealizador da Pedagogia da Relação e da Escuta em Reggio Emilia, desde o período inicial das escolas dirigidas pelos pais, elegeu como princípio orientador do bom senso coletivo "[...] que as coisas relativas às crianças e para as crianças somente são aprendidas através das próprias crianças" (MALAGUZZI, 1999, p. 61), contrapondo-se, assim, à visão adultocêntrica do processo educacional vigente. No decorrer dos anos, com a criação da primeira escola municipal para crianças pequenas, o desejo era

[...] reconhecer o direito de cada criança de ser um protagonista e a necessidade de manter a curiosidade espontânea de cada uma delas em um nível máximo. Tínhamos de preservar nossa decisão de aprender com as crianças, com os eventos e com as famílias, até o máximo de nossos limites profissionais, e manter uma prontidão para mudar pontos de vista, de modo a jamais termos certezas demasiadas. (MALAGUZZI, 1999, p. 62).

Assim, no exercício da atividade de professor e ao longo de sua atuação na administração pública educacional de Reggio, sempre se fundamentando em estudos sobre a educação da criança pequena, 
Malaguzzi “[...] elaborou e coordenou a construção de uma pedagogia singular [...]. Nem triste, nem melancólica, sem separar a teoria da prática e, mesmo sem escrevê-la academicamente, documentou e divulgou-a" (FARIA, 2007, p. 278). Essa Pedagogia coloca crianças, pais e professores como protagonistas, tendo em vista o objetivo de construir uma escola em que esses sujeitos se sentissem confortáveis, como se estivessem em casa. Para isso, Malaguzzi (1999) considerava necessário planejar cuidadosamente procedimentos, motivações, interesses e buscar maneiras de intensificar os relacionamentos entre crianças, pais e professores, garantindo a atenção aos problemas da educação, da participação e da pesquisa. Conforme o estudioso, tudo isso contribuía para que cada integrante da equipe tivesse consciência acerca das contribuições de todos para a estruturação de uma educação sustentada no relacionamento e na participação.

Rinaldi (2012) destaca que esta Pedagogia concebe e trata a criança de forma diferente, considerando-a como sujeito ativo, com o qual se pesquisa e se tenta encontrar significados para as coisas no cotidiano. Segundo a estudiosa e companheira de trabalho de Malaguzzi, é nessa busca de significados que se situa a origem da Pedagogia da Relação e da Escuta, uma das metáforas que distingue essa Pedagogia e o trabalho em Reggio. Como metáfora, escuta representa "[...] a abertura e sensibilidade de ouvir e ser ouvido - ouvir não somente com as orelhas, mas com todos os sentidos (visão, tato, olfato, paladar, audição e também direção)" (RINALDI, 2012, p. 124).

Nessa significação, o poema de Malaguzzi, amplamente conhecido como "As cem linguagens da criança", cuja denominação original é "Ao contrário, as cem existem", pode ser entendido como uma metáfora dessa Pedagogia, pois, ao mesmo tempo em que ressalta diversas linguagens que mostram a competência das crianças para se comunicar e se expressar, destaca o importante papel da escola, do professor e da sociedade na escuta e ampliação dessas linguagens.

Dessa forma, na Pedagogia da Relação e da Escuta, a escuta é importante para as crianças e para os adultos na significação de suas experiências, pois ela permite desenvolver a compreensão, por conseguinte, desenvolve "[...] uma teoria interpretativa, uma narrativa que dá significado ao mundo ao seu redor” (RINALDI, 2016, p. 234). Como enfatiza Rinaldi (2016, p. 234), “[...] essas teorias são extremamente importantes para revelar como as crianças pensam, questionam e interpretam a realidade, além do seu relacionamento com a realidade e conosco". A pesquisadora chama atenção, ainda, para o fato de que a comunicação de um sujeito para outro das teorias que elabora, sobre as experiências que vivencia, converte o mundo em algo a ser compartilhado.

Nesta ótica, é oportuno destacar que a valorização da "[...] escuta que ocorre dentro de 'um contexto que escuta', em que se aprende a ouvir e a narrar, possibilita que cada indivíduo se sinta legitimado para representar e oferecer interpretações de suas teorias, por meio de ação, emoção, expressão e representação", a partir das linguagens que dispõe (RINALDI, 2016, p. 236). Esta visão é coerente com a perspectiva de documentação pedagógica desenvolvida em Reggio (EDWARDS; GANDINI; FORMAN, 1999) e com a concepção de criança que fundamenta as práticas pedagógicas de Reggio. Nas palavras de Rinaldi (1999), as crianças são vistas como ricas, fortes e poderosas. 
A ênfase é colocada em vê-las como sujeitos únicos com direitos em vez de simplesmente com necessidades. Elas têm potencial, plasticidade, desejo de crescer, curiosidade, capacidade de maravilharem-se e o desejo de relacionarem-se com outras pessoas e de comunicarem-se. Sua necessidade e direito de comunicar-se e interagir com outros emerge ao nascer e é um elemento essencial para a sobrevivência e identificação com a espécie (RINALDI, 1999, p. 114).

Nesse contexto, destacamos que na abordagem reggiliana de Educação Infantil, a documentação pedagógica é tanto uma estratégia "para dar voz às crianças" e suas infâncias como um "[...] processo cooperativo que ajuda os professores a escutar e observar as crianças com que trabalham, possibilitando, assim, a construção de experiências significativas com elas" (GANDINI; GOLDHABER, 2002, p. 150). Dessa forma, a documentação pedagógica demanda a realização de diversos registros das experiências de aprendizagens vividas pelas crianças no dia a dia da Educação Infantil, dando visibilidade às suas vozes, preferências, gostos, curiosidades, interesses e necessidades, tanto no âmbito individual como no coletivo. De acordo com Dahlberg, Moss e Pence (2003), a documentação pedagógica como conteúdo é

[...] o material que registra o que as crianças estão dizendo e fazendo, é o trabalho das crianças e a maneira com que o pedagogo se relaciona com elas e com o seu trabalho. Tal material pode ser produzido de muitas maneiras e assumir muitas formas - por exemplo, observações manuscritas do que é dito e feito, registros em áudio e vídeo, fotografias, gráficos de computador, o próprio trabalho das crianças. Este material torna o trabalho pedagógico concreto e visível (ou audível) e, como tal, é um ingrediente importante para o processo da documentação pedagógica. (DAHLBERG; MOSS; PENCE, 2003, p. 194).

Importa pontuar que a observação na abordagem da documentação pedagógica idealizada por Malaguzzi, "[...] é uma forma de estar interessado e curioso para conhecer mais sobre a criança, o contexto e as formas de como é produzido o conhecimento" (FOCHI, 2015, p. 66). Segundo Fochi (2015), é por essa razão que Malaguzzi preferiu o uso da metáfora escuta, que se assenta no desejo do inesperado e da surpresa. Portanto, na perspectiva de Malaguzzi, “[...] trata-se de uma escuta ao inesperado, que nos coloca tanto em uma posição de surpresa com aquilo que pode acontecer, como em uma situação de atenção, pois não observamos para documentar o que já sabemos" (FOCHI, 2015, p. 67). Hoyuelos (2006, p. 121 apud FOCHI, 2015, p. 65) entende a escuta em Malaguzzi como “[...] estar alerta para deixar de considerar as coisas como naturais e óbvias, resgatando da evidência trivial o extraordinário, o inesperado que há nas palavras, gestos, nos desenhos e nos olhares das crianças".

Diante dessas proposições, entendemos que a documentação pedagógica no contexto da Pedagogia da Relação e da Escuta se fundamenta na necessidade de compreensão do ponto de vista das crianças, de sua capacidade de construir conhecimentos sobre de si e sobre o mundo e na capacidade do ser humano para se comunicar e elaborar teorias sobre as experiências que vivencia. Assim, relação, observação e escuta são aspectos indissociáveis e complementares do processo de elaboração individual e coletiva de significados. Isto porque a relação pressupõe a escuta, que por sua vez pressupõe a observação.

$\mathrm{Na}$ sequência, focalizaremos uma experiência de registro e acompanhamento do desenvolvimento das crianças, desenvolvida em uma instituição de Educação Infantil brasileira. 


\section{Unidade Universitária Federal de Educação Infantil Núcleo de Desenvolvimento da} Criança: um breve relato das práticas docentes relativas à avaliação

A Unidade Universitária Federal de Educação Infantil Núcleo de Desenvolvimento da Criança (UUNDC), da Universidade Federal do Ceará (UFC), é uma instituição pública federal de Educação Infantil que funciona em tempo parcial. Foi criada "[...] com a finalidade de integrar as atividades de ensino, pesquisa e extensão relacionadas com a criança na faixa etária correspondente à etapa da Educação Infantil e sua relação com a familia” (UNIVERSIDADE FEDERAL DO CEARÁ, 2013, p. 1).

É uma instituição de pequeno porte, cujo quadro docente é composto por cinco professoras; quatro atuam na docência com crianças e em ações de pesquisa e extensão e uma assume a função de diretora e coordenadora pedagógica da Unidade. Atualmente, ano de 2017, funcionam no turno da manhã dois agrupamentos de crianças, uma turma de Infantil 3 e uma de Infantil 4. No turno da tarde, funcionam uma turma de Infantil 4 e outra de Infantil $5^{6}$.

As práticas docentes de avaliação, portanto, de registro e acompanhamento do desenvolvimento das crianças e do trabalho desenvolvido junto a elas são realizadas pelas professoras por meio de inúmeras ações, como: 1) observação e escuta atenta e sensível das atividades, brincadeiras e interações das crianças entre si e com os adultos; 2) registro dos acontecimentos no grupo - registro escrito diário, fotografias e vídeos; 3) registro individual de cada criança - como age nos diferentes momentos da rotina, estando sozinha ou com seus pares, como constrói percursos na resolução de problemas e como organiza brincadeiras; 4) registro do projeto de aprendizagem em desenvolvimento na turma com a qual cada professora trabalha e do percurso de cada criança e do grupo ${ }^{7}$.

Assim, na UUNDC/UFC são realizados diversos registros (escritos, fotográficos e audiovisuais) das experiências de aprendizagem vivenciadas pelas crianças, decorrentes tanto de práticas pedagógicas planejadas pelas professoras como de atividades espontâneas das crianças. Esses registros fornecem subsídios às professoras para a documentação pedagógica que lhes possibilita conhecer mais e melhor as crianças, as singularidades de cada uma e do grupo. Estes também criam memória e possibilitam a reflexão sobre as experiências vividas, permitindo ainda que esta reflexão fundamente o planejamento de experiências futuras. Ressalta-se, assim, o alcance do processo de documentação pedagógica para a qualificação da prática pedagógica, pois assegura um planejamento baseado nos interesses e necessidades das crianças, trazendo-as para o centro do planejamento curricular.

Dessa forma, as práticas docentes de registro e acompanhamento do desenvolvimento das crianças e do trabalho desenvolvido junto a elas realizadas na UUNDC/UFC são fundamentais para a elaboração, pelas professoras, de documentação pedagógica específica que é entregue às famílias e passa a integrar o banco de dados da instituição, ao final de cada semestre, a saber: 1) Relatório geral da ação

6 Para conhecer um pouco mais sobre a UUNDC, ver Pereira e Silva (2015).

7 É importante pontuar que no trabalho de registro, as professoras contam com a colaboração de bolsistas, estudantes dos cursos de Pedagogia e Psicologia da UFC, que integram os projetos desenvolvidos na UUNDC/UFC, por exemplo, os de Extensão Universitária, de Pesquisa e de Iniciação Acadêmica. Esses estudantes são orientados e acompanhados pela professora da turma e pela coordenadora do projeto que integram. 
educativa desenvolvida com a turma com a qual trabalham, que permite às famílias das crianças e demais profissionais da UUNDC/UFC conhecerem as experiências de aprendizagem vivenciadas na Unidade durante o período; 2) Relatórios individuais de cada criança, com análises do seu desenvolvimento integral e das aprendizagens elaboradas e em processo, combinadas com descrições de diversos momentos vividos individualmente e junto às demais crianças da turma e da professora. Além dos mencionados relatórios, no final do ano é produzido, pelas professoras, e entregue às famílias das crianças, um portfólio ou livro de caráter narrativo, descritivo e analítico acerca das principais experiências de aprendizagem vividas pelas crianças e pela professora durante o Projeto de Aprendizagem desenvolvido na turma.

A seguir, inspiradas em Hoffmann (1996), apresentamos trechos de alguns relatórios individuais de crianças de turmas denominadas Infantil 2 e Infantil 3, produzidos no primeiro e segundo semestre dos anos de 2014, 2015 e 2016 por uma professora da UUNDC/UFC, uma das autoras desse ensaio ${ }^{8}$. Vale ponderar que nossa intenção, semelhante a de Hoffmann (1996), não é apresentar modelos; portanto, optamos por compartilhar apenas recortes de relatórios que nos originais são constituídos por oito a onze páginas. Deste modo, o compartilhamento de partes de relatórios individuais de crianças no contexto da Educação Infantil tem por finalidade ressaltar a necessidade imprescindível de observação, escuta e registro sensível das ações das crianças. Buscamos produzir uma documentação específica capaz de dar visibilidade às vozes das crianças, suas percepções, reações, preferências, ações, brincadeiras, sentimentos, enfim seus processos de desenvolvimento e aprendizagem nessa etapa da educação e seu protagonismo na construção de conhecimentos sobre si e sobre o mundo em que estão inseridas.

Acreditamos que cada professor, a partir de sua prática, da teoria educativa que a fundamenta e do contexto onde exerce a docência, é capaz de produzir seus relatórios. Estes, para representar o trabalho que o docente desenvolve junto às crianças e seus processos de desenvolvimento e aprendizagem, não podem seguir modelos ou receitas. Ao contrário, precisam representar fidedignamente sua prática e os processos de desenvolvimento e aprendizagem de cada criança no contexto específico de Educação Infantil do qual fazem parte.

Trechos de relatórios individuais de avaliação na educação infantil: a criança como protagonista

\section{Controle dos esfíncteres - Mônica9 (2 anos e 8 meses)}

Ao realizar suas necessidades fisiológicas, na fralda, Mônica não demonstra sentir-se incomodada e nem expressa a necessidade de trocar a fralda. Quando isso acontece, a troca de fralda é realizada assim que percebo. Nesses momentos, é com satisfação que Mônica pega sua mochila e vai para o banheiro.

\footnotetext{
8 As idades para matrícula das crianças nos agrupamentos denominados Infantil 2 e Infantil 3 na UUNDC são, respectivamente, 2 anos e 3 anos completos até 31 de março do ano em que for realizada a matrícula.

9 Todos os nomes das crianças referidos, neste ensaio, são fictícios.
} 
Durante a troca de fralda, sempre conversava com ela sobre seus objetos pessoais que estavam na mochila, bem como acerca das ações que ia realizar, por exemplo: tirar a fralda com xixi e colocar uma nova, passar pomada para não ficar assada. No início do primeiro semestre, Mônica escutava minhas comunicações verbais, observava atentamente o que estava acontecendo, mas não expressava por meio da fala o que sentia e o que pensava nesses momentos. Contudo, ao longo do semestre, demonstrou estar internalizando algumas dessas conversas e durante a troca de fraldas, passou a falar e fazer perguntas que expressam os diálogos que estabelecia com ela desde o início do ano. Vejamos:

Durante a troca de fraldas, ao ver sua pomada, Mônica fala: "Minha pomada, minha mamãe mandou pra mim não ficar assada". Depois da troca, ela olha para sua farda e diz: "Minha roupa da cola (escola)." Professora: "É Mônica, essa é sua roupa da escola, sua farda." Ao terminarmos de vestir sua roupa, ela olha para sua sandália e pergunta: "É a sandália da cola (escola) é?". Professora: "É sim, a sua sandália da escola.". Mônica então diz: "NDC", (apontando para sua blusa e falando) "aqui na blusa tem NDC." (como se dissesse: NDC é o nome da minha escola).

Para favorecer o processo de controle dos esfíncteres, estabeleci algumas combinações com os pais de Mônica. No decorrer do segundo semestre, ela ainda precisava da fralda para fazer suas necessidades fisiológicas, mas demonstrou interesse por ficar sem fralda, pois quando realizava a troca ela falava: "Professora, quero ficar só de calcinha". Assim, Mônica passou a vir para a Unidade sem fralda, mas logo notei que ela não estava mais fazendo xixi, nem cocô, durante toda a manhã. Em diálogo com a família, decidimos que ela permaneceria por mais tempo com a fralda. Em muitas das ocasiões de troca de fralda, ela fala: "Professora, vou fazer cocô no tronão" (apontando para o sanitário).

A partir desses dados que integram o relatório de Mônica, chamamos a atenção para aspectos próprios do trabalho docente na Educação Infantil, bastantes discutidos na literatura da área: a indissociabilidade do educar e cuidar, a necessidade de uma relação colaborativa com as famílias das crianças para encaminhar decisões relativas à educação das crianças e a importância de utilizar à linguagem oral para se comunicar com as crianças, mesmo quando elas não desenvolveram, ainda, esse tipo de comunicação. Nesse âmbito, destacamos que o trabalho docente nessa etapa da educação e a avaliação das crianças, que é parte integrante desse trabalho, sustentam-se numa concepção integrada de desenvolvimento e Educação Infantil, o que demanda não hierarquizar as atividades de cuidado e educação. (BARBOSA, 2000; BRASIL, 2009; CAMPOS, 1994).

\section{Transição casa-instituição de Educação Infantil - Luiza (2 anos e 8 meses)}

No início do semestre, custava muito para Luiza separar-se de seus familiares (mãe, pai, avó) e muitas vezes ela chorava ao despedir-se deles. Nesses momentos, tentava conversar com ela e animá-la a participar de alguma brincadeira ou escolher algo de sua preferência para realizar nos espaços diversificados da sala de atividades ${ }^{10}$. Contudo, às vezes Luiza não aceitava meu consolo e se jogava no

10 O arranjo espacial das salas de atividades da UUNDC é semiaberto. Assim, são formados cantinhos de interesse, denominados de áreas diversificadas. Atualmente há sete áreas fixas: área da dramatização (casinha), área dos blocos, área dos jogos, área da música, área de artes, área de leitura e área de Ciências. Há, ainda, espaço para a organização de áreas alternativas, feitas a 
chão, chorando. Nessas ocasiões, eu a colocava no braço e conversava com ela, explicando que logo seu pai ou sua mãe ou sua avó viriam buscá-la e que ela não podia se jogar no chão porque se machucaria. Assim, por meio de diálogos e negociações, progressivamente Luiza foi construindo mais segurança em sua convivência comigo e colegas na UUNDC. Em alguns momentos da rotina, ela expressava a vontade de estar junto de sua mãe e de seu pai, mas demonstrava um sentimento de confiança de que eles viriam buscá-la. Os relatos elucidam isso:

Durante as brincadeiras livres nos espaços diversificados da sala, Luiza pega o telefone, se aproxima da professora e fala: "Eu vou falar com minha mamãe." Professora: "Legal Luiza. Você vai telefonar para ela?" Com o telefone no ouvido, Luiza diz: "Vem me buscar aqui na escolinha." Professora: "O que sua mamãe falou, Luiza?" Luiza: "Disse que vai comprar suco de maçã pra mim.” Ela sai e vai guardar o telefone na área do escritório, encontra José [um colega da turma] no caminho e diz: "Eu falei com minha mãe.”

Luiza passeia pelo parque e fala para si mesma: “O meu papai vai chegar para mim buscar para casa."

Ressaltamos nesse recorte do relatório de Luiza, um importante aspecto que integra a avaliação na Educação Infantil, os momentos de transição vividos pela criança, neste caso, a transição casa/instituição de Educação Infantil (BRASIL, 2009). Assim, lembramos que o processo de inserção e de passagem da criança, da convivência no ambiente familiar para um novo espaço de convivência social, com rotinas, espaços, adultos e crianças desconhecidos exige dos docentes e das instituições o planejamento de estratégias adequadas para lidar com esse momento vivido pela criança, assim como, por sua família e pelos profissionais da instituição (BARBOSA, 2000; BRASIL, 2009). Elucidamos, ainda, a relevância de um olhar sensível, compreensivo e atento do professor para as necessidades de maior atenção as crianças nesses momentos e o estabelecimento de diálogo com as famílias.

\section{Expressão Verbal - César (2 anos e 8 meses)}

Ao longo do segundo semestre, observei que César teve avanços em sua comunicação por meio da linguagem oral; todavia sua fala articulada ainda não se consolidou. César fala muitas palavras (incompletas e completas), utilizando-as de forma contextualizada para se comunicar; além disso, progressivamente tem elaborado algumas frases em suas comunicações. Nesse sentido, cada vez mais temos ampliado as ações de conversar com ele, ler histórias, significar suas ações por meio da fala, estimulando-o a comunicar suas necessidades e desejos por meio da fala, a fim de ampliar cada vez mais suas interações verbais. Os relatos elucidam algumas interações verbais de César em diferentes momentos da rotina:

César e Ana estão na atividade de modelagem com massinha. Ana observa o brinquedo que César trouxe de casa e faz um semelhante. Ela olha para o colega, mostra sua modelagem e diz: "Um ovo, César." César fala: "Ovo, ovo." Depois de algum tempo na modelagem, Ana imita um avião abrindo os braços e diz: "Avião" (Dentro do ovo trazido por César tinha um avião). César imita os gestos de Ana e ela fala: "Ele me

partir das demandas do grupo de crianças. No planejamento das atividades, é destinada uma hora, todos os dias, para aquelas de livre escolha das crianças nessas áreas. 
imitou.” César diz: “ão, ão” (avião).

Estou na área dos jogos e escuto César gritar: "Sorra! Sorra!” (professora). Quando olho, ele está na área da casinha, próximo da rede e diz: "Umí, umín" (dormir). Professora: "Você quer dormir, César?" César balança a cabeça em gesto afirmativo. Professora: "Então deita na rede, vou pedir a Luiza, sua amiga, para te balançar, pois estou ocupada agora." Ele deita e Luiza que estava brincando na casinha o balança carinhosamente.

César tenta ligar o som e não consegue. Ele vem aonde estou, pega na minha mão e me leva até o som e diz: "Musca, musca" (música). Professora: "Você quer ouvir música, César? Vou colocar o CD no som e ligar." Quando a música começa, ele dança pulando e sorrindo.

\section{Expressão Verbal - Luiza (2 anos e 8 meses)}

Luiza comunica-se de maneira compreensível por meio da linguagem oral e no decorrer do semestre cada vez mais a utilizava para comunicar suas ideias, percepções, necessidades, interesses e curiosidades. Tem um vocabulário amplo e passou a utilizar em seus diálogos os pronomes pessoais, "eu" e "tu", o que demonstra a progressiva construção da consciência de si e do outro. Luiza compreende o que lhe é dito e em diferentes situações da rotina, fala para si mesma, interage verbalmente com os colegas e com as professoras. Observemos alguns registros de suas interações verbais:

Luiza brinca no espaço das artes; ela está utilizando a massinha. Desloca-se até a professora e diz: "Toma, eu terminei" Professora: “O que você fez, Luiza?” Luiza: "Um bolo confeitado para tu." Professora: "Hum! Obrigada, vou comer agora mesmo, deve estar uma delícia." Luiza sorri e volta para a modelagem.

Luiza está brincando no espaço da casinha. Ela nota a presença da professora, olha para o baú das fantasias e diz: "Eu quero a Branca de Neve" Professora: "Você quer a fantasia da Branca de Neve, Luiza?" Luiza: "Sim." Professora: "Pode pegar no baú." Ela procura a fantasia e ao encontrá-la, entrega à professora como se dissesse "me ajuda a vestir'. Com o auxílio da professora, ela veste a fantasia e passeia contente pela sala.

Luiza brinca no balanço com César, ela faz carinho no rosto dele, passando a mão e dizendo: "Eu to fazendo carinho no César."

Luiza, José e César folheiam o livro da história "Bruxa, bruxa venha à minha festa" na mesa próximo ao cantinho da leitura. Luiza segura o livro e diz: "Eu vou ler sozinha para vocês”. José aponta para os personagens e pergunta a Luiza: “Quem é esse? É a chapeuzinho vermelho?" Luiza folheia o livro e ao ver os personagens fala com expressividade: "Gato, gato; coruja, coruja; tubarão, tubarão; fantasma, fantasma." Ao ver o Babuíno, José fala: "Babuíno, Babuíno, venha a minha festa." Luiza se distrai e César pega o livro e começa a folhear. Luiza tenta pegá-lo de volta. Professora: "Luiza, deixa o César ler um pouco para vocês." Luiza aceita, mas logo pega outro livro na estante, o da história "O ratinho, o morango vermelho maduro e o grande urso esfomeado". Ela olha para José e pergunta: "Você gosta?" José não responde e Luiza começa a folhear o livro.

Em relação aos extratos dos relatórios de César e Luiza (ambos com 2 anos e 8 meses), os quais enfocam um mesmo aspecto do desenvolvimento, a expressão verbal, destacamos uma demanda imprescindível à avaliação na Educação Infantil. Referimo-nos ao fato de que é preciso olhar o desenvolvimento e as aprendizagens das crianças como um processo que ocorre em um contexto e apresenta singularidades. Lembramos, ainda, que as relações, as interações e as práticas cotidianas que a 
criança vivencia são imprescindíveis para ampliar seu desenvolvimento e suas aprendizagens (BRASIL, 2009; EDWARDS, C; GANDINI, L.; FORMAN, G., 1999). Assim, enfatizamos que a competência da criança em uma linguagem não pode ser comparada com a de outra criança, por exemplo, porque as duas tem a mesma idade.

\section{Expressão Plástica - Paloma (3 anos e 8 meses)}

Nas experiências de expressão plástica, incluindo desenhos, pinturas ou modelagens, Paloma demonstrou animação ao participar. Ao longo do ano, seus desenhos evoluíram significativamente, gradualmente passaram a ganhar nomes e formas mais elaboradas, sendo notável, por exemplo, a representação de figuras humanas e de cenas de suas histórias preferidas. Em relação às representações de histórias, algumas vezes fez desenhos de memória das cenas que mais apreciou durante a leitura. Vejamos duas produções da história "A Casa Sonolenta", que Paloma desenhou (sem consulta ao livro) logo após a leitura realizada pela professora, ambas bastante representativas do que é ilustrado na página do livro que retrata as cenas representadas por meio do desenho:

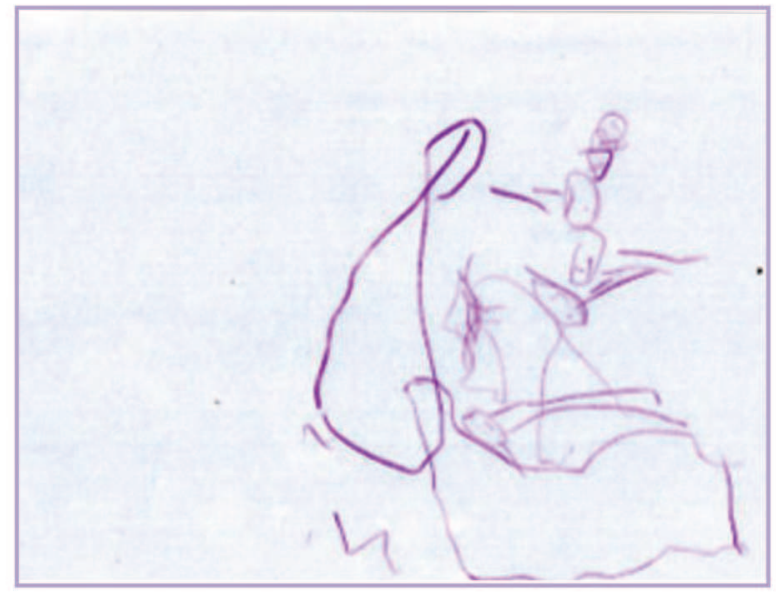

Ao terminar o primeiro desenho Paloma diz: "A cama, fiz todos, eles tão dormindo."

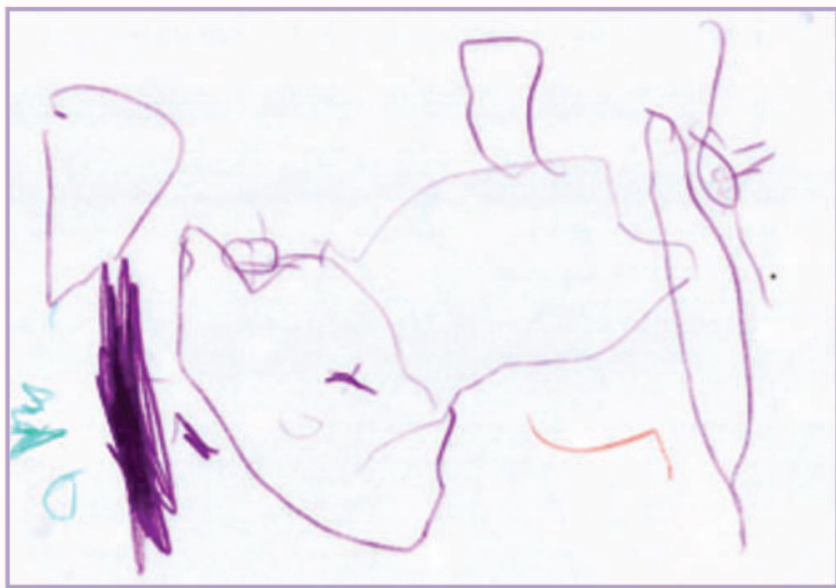

Ao terminar o segundo desenho Paloma diz: "Aqui é a cama, eles acordaram." 


\section{Expressão Plástica - Jamile (4 anos e 2 meses)}

Jamile envolvia-se muito na produção de desenhos. Diversas vezes desenhava sua família. Nessas ocasiões ela dizia: "Professora, vou fazer minha familia." Vejamos um desenho e o relato que acompanhou sua construção. Foi feito em uma dessas ocasiões, a partir da observação de uma foto em que ela está com seu pai e sua mãe:

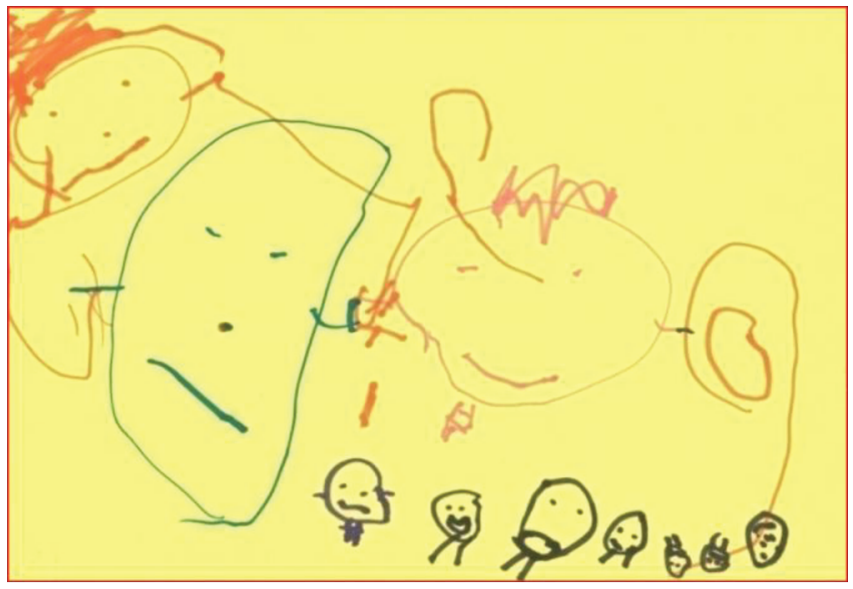

Antes de iniciar o desenho, Jamile observa a foto. A professora pergunta: "Quem você vai fazer primeiro, Jamile?" Jamile: "Eu" Ela escolhe o rosa e ao terminar fala: "Prontinho, ficou bem feito, falta fazer o cabelo" Professora: "Ficou mesmo, e agora você vai fazer quem?" Jamile: "O meu pai." Ela desenha e fala: "A cabeça dele é grandona. Olha, ele tá bravo." Ao terminar, pega a canetinha laranja. Professora: "Agora você vai desenhar quem?" Jamile: "Minha mãe, minha mãe tem cabelo cacheado." Jamile termina e observa o desenho. Professora: "Você terminou ou ainda falta alguém?" Jamile: "Não, ainda falta minha vó e meu vô." Ela pega o lilás, desenha e diz: "Prontinho fiz meu vô, agora vou fazer minha vó, taqui (ta aqui) ela sorrindo. Agora falta a vovó Tea." Ela faz a vovó e depois faz vários desenhos. Professora: "Quem está do lado da vovó Tea?" Jamile: "O Ruan" Professora: "Quem é o Ruan?" Jamile: "Meu primo. Pronto, agora o vovô Valmir. Pronto aqui minha família. Ai, falta a Ludimila" Professora: "Quem é a Ludimila, Jamile?" Jamile: “É a minha prima. Aqui é a mãe dela e o pai dela que falta. A família toda, eu desenhei toda minha família."

O relato expressa como Jamile se organizou para produzir sua obra, revelando, ainda, o conhecimento detalhado que possui de muitas pessoas da sua família, as quais reunidas no desenho integram um todo, como ela verbalizou contente e expressivamente. Após concluir seu desenho, disse: "A familia toda, eu desenhei toda minha família."

Considerando os dados reunidos nos segmentos dos relatórios de Paloma e Jamile, sublinhamos a relevância de que, no âmbito da avaliação na Educação Infantil, as múltiplas linguagens das crianças (MALAGUZZI, 1999) sejam enfocadas. Neste campo, apresentamos o desenho, que integra outras linguagens, como exemplo de uma importante linguagem da criança, uma forma de representação simbólica que ela utiliza para expressar a forma como percebe o meio em que está inserida e as experiências que vivencia. Ressaltamos, ainda, que o objetivo da Educação Infantil, reafirmado no Art. $8^{\circ}$ das DCNEI/2009, inclui o acesso a processos de apropriação, renovação e articulação de conhecimentos e aprendizagens de diferentes linguagens (BRASIL, 2009). 


\section{Relacionamento com a professora e com os pares -}

\section{Débora (3 anos e 2 meses)}

No início do semestre, Débora pouco aceitava as minhas manifestações de carinho e apresentava atitudes que demonstravam pouco interesse em interagir comigo, com as outras professoras e com crianças do grupo, negando qualquer contato físico ou até mesmo verbal. Contudo, insisti nas manifestações de carinho e nos convites para brincar com ela. Progressivamente, Débora foi se aproximando e passou a confiar em mim e a corresponder às minhas demonstrações de afeto por meio de abraços, beijos e do aceite em compartilhar brincadeiras comigo e com os colegas. Assim, no decorrer do semestre, Débora cada vez mais se relacionava de forma tranquila com a professora e com os colegas, compartilhava jogos e brinquedos, mostrando-se delicada, cuidadosa com os amigos e carinhosa em suas ações. O relato a seguir ilustra um rico momento de interação e brincadeira de Débora com um colega, em que muitos de seus progressos e características pessoais tornam-se bem evidentes.

Débora e César (2 anos e 2 meses) vão com a professora brincar no parque grande. Saímos os três de mãos dadas e, ao chegarmos no parque, Débora diz: "Olha César, como é grande esse parque." Ela solta a mão dele e César diz, esticando o braço na direção de Débora: "Mão, mão." Débora então pega novamente na mão dele. César aponta para o escorregador e Débora fala: "É muito alto César, é muito alto pra você, vem!" (e sai andando em direção a um brinquedo menor). César não a segue e sobe no escorregador, Débora então diz novamente: "César é muito alto pra você, você cai." César sobe e desce e Débora fala: "Olha professora, ele não cai" Professora: "Ele já aprendeu a subir e descer, Débora." Débora observa ele brincando e diz carinhosamente: "Vai, vai, olha você consegue, agora é minha vez." César sai do escorregador e senta no balanço sozinho e Débora fala: "Olha professora, ele está balançando" Professora: "Está sim." César volta para o escorregador e Débora o estimula a subir dizendo: "Vai, coloca um pé e depois o outro." Quando ele sobe, ela pronuncia empolgada: "Eita, como você é esperto, você não cai. Agora é minha vez".

\section{Relacionamento com pares (Conflitos) - Laura (3 anos e 11 meses)}

Notamos que era difícil para Laura controlar o seu envolvimento em conflitos interpessoais, comuns em sua faixa etária, especialmente pela disputa de espaços, materiais e brinquedos; contudo, foram menos frequentes as ocasiões em que isso aconteceu no decorrer do segundo semestre. Com a mediação da professora, paulatinamente ela passou a compartilhar espaços e brinquedos com os colegas. Vejamos:

Jamile, Talita, Paloma e Laura estão brincando com os brinquedos de areia. Laura toma a colher de Jamile. Me aproximo e explico que ela não pode tomar a colher da colega, pois ela estava usando e pegou primeiro e que tem outras colheres para Laura usar. Peço à Laura que devolva a colher à Jamile e sugiro que vá pegar outra para si. Laura se recusa, segurando a colher e dizendo: "Não, é minha." Insisto para ela devolver e com a minha ajuda ela devolve. Em seguida, ela olha para Aline e diz: "Vamos, Aline, vamos correr juntas." As duas escolhem outros brinquedos de areia e vão brincar. Elas sentam longe de Jamile, Talita e Paloma. Me aproximo e sugiro que elas sentem perto das colegas. Laura diz: "Tá bom." Ao chegar perto das amigas, Laura pergunta: "Paloma, posso brincar com vocês?" Paloma: "Sim." Aline e Laura sentam perto das amigas e Laura fala: "Pronto, agora dá certo." Olha para Jamile e diz: "Agora eu entendi." (olhando para a colher da amiga), "Eu tenho uma colher vermelha." 
Ao analisarmos os trechos dos relatórios de Débora e Laura, destacamos a peculiaridade da mediação do professor no campo das relações interpessoais das crianças com seus pares, tanto em situações de conflito como em situações nas quais é preciso ampliar suas relações. É necessário pontuar que este tipo de mediação exige do profissional o desenvolvimento de ações marcadas pela observação, escuta e diálogo com a criança (BARBOSA; FERNANDES, 2012; FORTUNATI, 2012; RINALDI, 2016). É oportuno ressaltar que o mencionado diálogo precisa amparar-se em princípios éticos que devem orientar as interações adulto/criança, tendo em vista o atendimento aos seus direitos, por exemplo: “[...] à proteção, à saúde, à liberdade, à confiança, ao respeito, à dignidade, à brincadeira, à convivência e à interação com outras crianças” (BRASIL, 2009, p. 5).

\section{Preferências durante as atividades de livre escolha nos espaços diversificados da sala - Victor (3 anos e 7 meses)}

Victor explorou os diferentes espaços, materiais e brinquedos da sala de atividades, mas esteve mais envolvido no espaço da casinha, na área dos blocos e no cantinho da leitura. Era com animação que escolhia a fantasia do Batman (sua preferida) e brincava de super-herói com os colegas. Também gostava de brincar de pai, mãe e filha com suas colegas, tendo preferência pelo papel de pai. No cantinho da leitura, folheava os livros de suas histórias preferidas e nos blocos se envolvia muito na construção de estradas e torres. O relato contempla momentos de Victor durante as atividades de livre escolha:

\footnotetext{
Victor e Paloma arrumam as roupas do baú de fantasias; eles colocam as roupas nos cabides ao lado do baú. Depois de um tempo, Paloma, que está usando o vestido da Branca de Neve, se aproxima de mim e Victor fala: "Ela quer trocar de roupa." Ajudo Paloma a tirar o vestido e ela escolhe uma blusa; tenta vestir sozinha, como não consegue vem até mim e diz: "Quero vestir." Professora: "Certo Paloma, vou ajudar você." Carine se aproxima do cabide e Victor fala: "É as roupas minhas e da Paloma. É dois reais." (como se estivessem à venda). Carine se aproxima de mim e fala: "Quero tirar" (o vestido da Minie que estava usando). Professora: "Certo, vamos tirar o vestido da Minie." Em seguida ela vai até o cabide e escolhe outro vestido. Victor observa e não diz nada. Paloma tira a blusa que estava usando e fala contente: "Tirei professora." Professora: "Maravilha Paloma, você já consegue tirar a blusa." Victor, que está usando a fantasia do Homem-Aranha, pega a do Superman e diz para si mesmo: "Quero trocar de roupa." Ele tira sozinho a fantasia e veste a outra. Paloma fala: "Professora vou trocar de roupa." Victor escuta e diz: "De novo, Paloma." Paloma sorri e fala: "Victor..." Paloma traz o vestido da Branca de Neve (o que ela estava vestida antes) me entrega e fala: "Quero vestir." Professora: "Vou ajudar você a vestir, Paloma."
}

Nos dados do relatório de Victor, apresentados aqui, ressaltamos uma importante dimensão do trabalho pedagógico na Educação Infantil que necessita ser contemplada no processo de acompanhamento do desenvolvimento e das aprendizagens das crianças - a brincadeira - a qual junto com as interações constituem os eixos norteadores das práticas pedagógicas em creches e pré-escolas (BRASIL, 2009). Assim, o entendimento da brincadeira como linguagem própria da criança e como atividade necessária para seu desenvolvimento e aprendizagem, bem como a familiaridade com as diversas formas de brincadeiras na faixa etária da Educação Infantil, compõem conhecimentos necessários ao professor 
dessa etapa da educação, uma vez que, ele precisará observar, registrar e analisar as brincadeiras das crianças.

\section{Considerações finais}

No decorrer deste ensaio, incluímos aportes teóricos e excertos de relatórios individuais, resultantes do processo de avaliação do desenvolvimento e aprendizagens de crianças de uma instituição de Educação Infantil, com o objetivo de contribuir para o debate acerca da avaliação nesta primeira etapa da educação básica em nosso país. Vale ressaltar que permeia esse artigo o conceito de avaliação como prática de registro e acompanhamento do desenvolvimento das crianças, que resulta na produção de documentação pedagógica específica sobre os processos de desenvolvimento e aprendizagem das crianças nessa etapa educacional.

Ao concluirmos este texto, é imprescindível ressaltar que os relatórios, que tiveram alguns recortes apresentados aqui, foram construídos numa perspectiva mediadora de avaliação. Esta, segundo Hoffmann (1996), possui as seguintes características: transparece os objetivos que norteiam a análise do desenvolvimento da criança; mostra a inter-relação entre os diferentes objetivos sociais, afetivos e cognitivos e as ações das crianças; revela a atitude mediadora do processo de avaliação; prioriza, no decorrer do relatório, o caráter evolutivo do processo de desenvolvimento da criança e demonstra as especificidades do acompanhamento individual de cada criança.

Destacamos, também, que as narrativas e descrições das experiências de aprendizagens vividas pelas crianças no cotidiano da Educação Infantil, sistematizadas nos relatórios apresentados, foram subsidiadas pela análise docente das expressões verbais, gestuais e plásticas das crianças, de suas interações e brincadeiras, bem como da participação de cada criança nos diferentes momentos da rotina, documentadas pela professora e bolsistas da turma. Nesta perspectiva, concluímos que os relatórios tornaram visíveis o desenvolvimento e as aprendizagens das crianças, cumprindo, assim, uma das funções da documentação pedagógica.

Desse modo, consideramos que a documentação pedagógica que inclui o registro das falas e ações das crianças (escrito e audiovisual), de suas expressões (fotográfico e audiovisual) e de suas produções (desenhos, modelagens, pinturas, construções etc.) constitui um recurso imprescindível para a avaliação na primeira etapa da Educação Básica. Como afirma Hoffmann (1996, p. 48) a documentação contribui para resgatar o sentido essencial da avaliação na Educação Infantil, qual seja: "[...] de acompanhamento do desenvolvimento e de reflexão permanente sobre as crianças em seu cotidiano, como elo na continuidade da ação pedagógica" (p. 48). Rinaldi (2001), em consonância com essa ideia, pondera que a documentação constitui, pois, uma ferramenta que pode revelar a singularidade dos caminhos que as crianças estão percorrendo para aprender, incentivando-os a refletirem sobre suas práticas. 
Ademais, ressaltamos que os relatos das falas das crianças demonstram seu protagonismo na construção de conhecimentos, alertando que as Pedagogias de cunho assistencialista, escolarizante e transmissivo desconsideram a competência das crianças para agir e elaborar significados para o que vivenciam. Além disso, as falas das crianças revelam que a avaliação na Educação Infantil pressupõe uma prática docente que não reproduz o estilo de avaliação das demais etapas da educação, mas que respeita os processos de desenvolvimento e aprendizagem das crianças.

A partir do que foi apresentado e discutido, acreditamos ser possível afirmar que a produção de documentação pedagógica possibilita a análise e a interpretação do ponto de vista das crianças, permitindo a desconstrução de formas abstratas e muitas vezes preconceituosas de pensar a infância, a criança, a aprendizagem, o currículo e a avaliação na Educação Infantil. Muitas vezes, estas formas impedem o docente de ver as crianças, suas famílias, suas culturas e a si mesmos, a partir de experiências concretas vivenciadas no cotidiano da Educação Infantil.

No âmbito dessa discussão, não podemos deixar de ressaltar que a prática de documentação pedagógica e a avaliação mediadora na Educação Infantil envolvem inúmeros desafios e aprendizagens “[...] tanto no nível da (auto) formação do professor quanto no nível do sistema educacional, de gestão e organização interna das instituições de educação infantil” (BARBOSA; FERNANDES, 2012, p. 10). Estes desafios ocorrem porque a opção pela documentação pedagógica como prática docente necessária para que a avaliação na Educação Infantil cumpra sua finalidade de registrar e acompanhar o desenvolvimento das crianças significa demandas adicionais para a gestão educacional e escolar dessa etapa da educação.

Nesse sentido, é necessário mencionarmos que a avaliação na Educação Infantil não é uma questão que deve ser direcionada apenas para instituição e para o professor, mas que deve ser debatida no contexto das políticas públicas de Educação Infantil. Nesse ponto, enfatizamos que o trabalho docente em turmas de creches e pré-escolas envolve as formas de organização do trabalho institucional, que integram elementos próprios à composição das equipes de profissionais docentes, como: formação, jornada, carreira e valorização.

Assim, finalizamos este ensaio ressaltando que a prática de avaliação na Educação Infantil, definida na legislação educacional brasileira, exige do professor tanto a competência para observar, escutar, registrar e "[...] perceber os significados das ações e do comportamento das crianças quanto a habilidade para encontrar palavras adequadas para descrever e interpretar tal comportamento sem diminuir-lhe o valor" (FORTUNATI, 2012, p. 6). No entanto, para que os professores possam desempenhar com competência suas funções, é imprescindível a garantia de seus direitos ${ }^{11}$ que, por sua vez, exigem investimentos do poder público.

Concluímos ressaltando que o objetivo da avaliação na Educação Infantil está definido e os desafios para sua consecução sempre permearam a trajetória desta etapa da educação em nosso país.

\footnotetext{
11 Entre tantos outros exemplos possíveis, citamos dois: 1) formação inicial e continuada que contemple a especificidade da Educação Infantil; 2) horas para planejamento e produção de documentação específica prevista na jornada de trabalho, compatível com o tempo necessário para sua realização. Nunca é demais lembrar que se o professor trabalha com 20 crianças, é necessário prever em sua jornada de trabalho um tempo para a escrita de 20 relatórios individuais e um relatório geral do trabalho desenvolvido em cada semestre; caso seja essa a documentação específica adotada na instituição em que trabalha.
} 
Desse modo, questionamos: O que tem sido feito? A resposta a essa questão ressalta a necessidade da realização de estudos e pesquisas que nos permitam conhecer como de fato está acontecendo a avaliação do trabalho pedagógico e das crianças em instituições de Educação Infantil brasileiras.

Ademais, as reflexões elaboradas neste ensaio demostraram que a documentação sistemática do desenvolvimento e das aprendizagens das crianças exige a presença, no dia a dia da Educação Infantil, de uma Pedagogia edificada com base na escuta da criança e na observação atenta e sensível de suas relações e interações com o mundo físico e social. Nesse sentido, a Pedagogia da Relação e da Escuta é uma importante inspiração para edificação de Pedagogias da Educação Infantil que respeitem os direitos das crianças e que subsidiem uma avaliação de sua experiência educativa capaz de representar os processos de desenvolvimento e aprendizagem conquistados e aqueles em desenvolvimento.

\section{Referências}

AZANHA, J. M. P. Uma idéia de pesquisa educacional. São Paulo: EDUSP, 1992.

BARBOSA, M. C. S. Por amor \& por força: rotinas na Educação Infantil. 2000. 283 f. Tese (Doutorado em Educação) - Faculdade de Educação, Universidade Estadual de Campinas, Campinas, 2000.

BARBOSA, M. C. S. B.; FERNANDES, S. B. Uma ferramenta para educar-se e educar de outro modo. Pátio - Educação Infantil, ano X, n. 30, p. 9-11, jan./mar. 2012.

BRASIL. Congresso Nacional. Lei n. 9.394/96, de 20 de dezembro de 1996. Estabelece as Diretrizes e Bases da Educação Nacional. Brasília, DF, 1996.

BRASIL. Ministério da Educação. Conselho Nacional de Educação. Câmara de Educação Básica. Resolução n. 5, de 17/12/2009. Diretrizes Curriculares Nacionais para a Educação Infantil. Brasília, DF, 2009.

CAMPOS, M. M. A legislação e as políticas nacionais para a educação infantil: desencontros e desafios. In: MACHADO, M. L. A. Encontros e desencontros em Educação Infantil. São Paulo: Cortez, 2008. p. 27-33.

CAMPOS, Maria Malta. Questões Sobre o Perfil do Profissional de Educação Infantil. In: Por uma política de formação do profissional de educação infantil. Brasília, DF, 1994. p. 32-42.

CIASCA, M. I. F. L.; MENDES, D. L. L. L. Estudos de avaliação na educação infantil. Est. Aval. Educ., São Paulo, v. 20, n. 43, p. 293-304, maio/ago. 2009.

DAhlberG, G.; MOSS, P.; PENCE, A. Qualidade na Educação da Primeira Infância. Porto Alegre: Artmed, 2003. 
EDWARDS, C.; GANDINI, L.; FORMAN, G. As cem linguagens da criança: a abordagem de Reggio Emília na educação da primeira infância. Porto Alegre: Artmed, 1999.

FARIA, A. L. G. Loris Malaguzzi e os direitos das crianças pequenas. In: OLIVEIRA-FORMOSINHO, J.; KISHIMOTO, T. M.; PINAZZA, M. A. (Orgs.). Pedagogia(s) da infância: dialogando com o passado, construindo o futuro. Porto Alegre: Artmed, 2007. p. 277-292.

FOCHI, P. Afinal, o que os bebês fazem no berçário? Comunicação, autonomia e saber-fazer de bebês em um contexto de vida coletiva. Porto Alegre: Penso, 2015.

FORTUNATI, A. A observação como instrumento para conhecer, contar e refletir. Pátio - Educação Infantil, ano X, n. 30, p. 5-7, jan./mar. 2012.

GANDINI, L.; GOLDHABER, J. Duas Reflexões sobre a Documentação. In: GANDINI, L.; EDWARDS, C. (Orgs.). Bambini: a abordagem italiana à educação infantil. Porto Alegre: Artmed, 2002. p. $150-169$.

HOFFMANN, J. M. L. Avaliação na pré-escola: um olhar sensível e reflexivo sobre a criança. Porto Alegre: Mediação, 1996.

MALAGUZZI, L. História, ideias e filosofia básica. In: EDWARDS, C.; GANDINI, L.; FORMAN, G. As cem linguagens da criança: a abordagem de Reggio Emília na educação da primeira infância. Porto Alegre: Artmed, 1999. p. 59-104.

NEVES, V. F. A. Avaliação na educação infantil: algumas reflexões. In: Reunião anual da ANPED, GT 07 - Educação de crianças de 0 a 6 anos, 35, 2012, Pernambuco. Anais eletrônicos. Pernambuco: ANPED, 2012. Disponível em: <http://35reuniao.anped.org.br/trabalhos/106-gt07>. Acesso em: 10 jan. 2015.

PAZ, S. J. P. A avaliação na educação infantil: análise da produção acadêmica brasileira presente nas reuniões anuais da ANPEd entre 1993 e 2003. 2013. 133f. Dissertação (Mestrado em Educação) Universidade Federal de Santa Catarina, Florianópolis, 2005.

PEREIRA, J. R.; SILVA, F. S. A extensão e o ensino na unidade universitária federal de educação infantil núcleo de desenvolvimento da criança. Extensão em Ação, Fortaleza, v. 1, n. 8, p.15-28. Jan/Jul. 2015.

RINALDI, C. O currículo emergente e o construtivismo social. In: EDWARDS, C.; GANDINI, L.; FORMAN, G. (Orgs.). As cem linguagens da criança: a abordagem de Reggio Emília na educação da primeira infância. Porto Alegre: Artmed, 1999. p. 113-122.

RINALDI, C. Diálogos com Reggio Emilia: escutar, investigar e aprender. São Paulo: Paz e terra, 2012. 
RINALDI, C. A pedagogia da escuta: a perspectiva da escuta em Reggio Emilia. In: EDWARDS, C.; GANDINI, L.; FORMAN, G. (Orgs.). As cem linguagens da criança: a experiência de Reggio Emilia em transformação. Porto Alegre: Penso, 2016. p. 235-248.

UNIVERSIDADE FEDERAL DO CEARÁ. Resolução $\mathbf{n}^{\circ}$ 02/CONSUNI, de 25 de fevereiro de 2013. Aprova, ad referendum do Conselho Universitário, a criação da Unidade Universitária de Educação Infantil, Núcleo de Desenvolvimento da Criança (NDC), vinculada ao Centro de Ciências Agrárias da UFC. UFC, 2013 